\section{Perceptions of social impacts likely drive feelings about MPAs}

Negative attitudes toward established MPAs may have less to do with the actual impacts on one's ability to go fishing, but more to do with the perceived impacts on their wellbeing through feelings of fear, stress and injustice. Extractive users nearly all reported negative perceptions of the park, despite only two reporting increased financial costs. Those who held strong negative attitudes did not perceive any environmental benefits. The consultation process itself may have helped formulate negative perceptions of the park, after clear concessions were made to the commercial lobster fishing industry but not to other groups.

The authors focused this study on the Jurien Bay Marine Park ("the Park") located 200 $\mathrm{km}$ north of Perth, Australia. Declared in 2003, the Park is a multi-use MPA managed by the Department of Biodiversity, Conservation and Attractions, covering more than 82,000 ha of water. In 2005, six zone types were added through an iterative consultation process with local stakeholder groups and a community advisory committee. Using semi-structured interviews with 50 members of these groups and representatives, the authors sought to determine the perceived social impacts of the Park to these stakeholders.

The authors determined that individuals across all stakeholder groups held negatives attitudes toward the marine park in some form or another. Most commonly, these were negative feelings toward the current management plan or the Department of Biodiversity, Conservation and Attractions itself. However, for those who reported feelings of injustice or inequality, negative attitudes were usually held toward the decision-making and consultation processes. Negative impacts were nearly exclusively reported by those who used the park for extractive purposes (for example, commercial fishing). Strong negative emotions that were commonly shared included fear, stress, betrayal and discrimination. Interestingly, negative impacts of the Park were reported more often by the representatives of the recreational fishing community than local, recreational fishers themselves.

Positive impacts from the establishment of the Park were reported more often by those who used the park for non-extractive purposes, like recreational activities and the tourism industry. These positive feelings toward the park were centered mainly on longterm benefits, such as attracting tourists and raising awareness about the local marine environment.

Respondents "who reported negative impacts also saw little or no positive impacts and displayed negative evaluations of the park." This was also true in reverse, as those who reported positive benefits reported few negative attitudes toward the Park. "No stakeholders who experienced significant negative impacts recognised any environmental benefits."

It is important to note that feelings of fear and stress from the establishment of the Park were not because of immediate financial impacts -- increased financial costs were only reported by two people who were both commercial fishers. However, fishers "described continually watching their locations while on the water to prevent fishing in the wrong zone by mistake, making fishing a less enjoyable experience". The addition of new regulations
This is a summary of: Attitudes to a marine protected area are associated with perceived social impacts

Accessible at: https://marxiv.org/8kuyw

Authors: Asha McNeill, Julian Clifton, Euan S. Harvey

Added to MarXiv: May 2018

Published: Marine Policy, 2018

Suggested Citation: Attitudes to a marine protected area are associated with perceived social impacts. OCTO (2018). DOI: 10.17605/OSF IO/S9F8R

See more MarXiv summaries at https://www.marxivinfo.org/ summaries

Share your research in MarXiv and the MarXiv Team may summarize it, just like this!

Step-by-step instructions on how to share your research in MarXiv are detailed at https://www.marxivinfo.org/ submission

Across all disciplines, papers available for free with a preprint (also known as "Green OA") are cited $30 \%$ more than the world average (DOI: 10.7287/peerj. preprints.3119v1) 
with the establishment of the Park, combined with existing management rules, likely contributed to regulation fatigue. Fishers reported stress from the added limitations on their ability to fish, and confusion related to these regulations all working together.

The community consultation process itself may have helped to breed negative feelings toward the Park. Recreational fishing industry representatives reported strong feelings of injustice and inequality as the commercial fishing industry was able to lobby for regulations that allowed for unfettered access for lobster fishing. A member of the community advisory committee probably put it best: "Having a dozen people all with different views sitting in a room arguing about squares on a map is not only ineffective in achieving the objectives that they really all want, but it's awfully damaging."

\section{MarXiv}

The MarXiv Team

Nick Wehner,

Director of Open Initiatives, OCTO

Raye Evrard,

Project Manager, ОСтO

Allie Brown,

Project Associate, ОСто

Sarah Carr,

Chief Knowledge Broker,

OCTO

John Davis,

President, OCTO

\section{Correspondence}

Nick Wehner

nick@octogroup.org

Financial support for MarXiv comes from the David and Lucile Packard Foundation.

The views expressed herein are those of the MarXiv Team and should not be interpreted as representing the opinions or policies of the Packard Foundation or other funders of MarXiv.

Join the MarXiv Summaries monthly newsletter at https:// oct.to/marxivsum

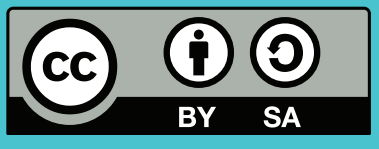

MarXiv is an ОСТO Initiative
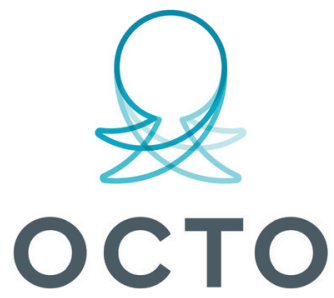

OPEN COMMUNICATIONS FOR THE OCEAN 